\title{
Massif forestier de Réno-Valdieu
}

\section{Fabrice Morand}

URL : https://journals.openedition.org/adlfi/3807

ISSN : 2114-0502

Éditeur

Ministère de la Culture

Référence électronique

Fabrice Morand, « Massif forestier de Réno-Valdieu » [notice archéologique], ADLFI. Archéologie de la France - Informations [En ligne], Normandie, mis en ligne le 01 mars 2009, consulté le 22 juin 2021.

URL : http://journals.openedition.org/adlfi/3807

Ce document a été généré automatiquement le 22 juin 2021.

(c) ministère de la Culture et de la Communication, CNRS 


\section{Massif forestier de Réno-Valdieu}

Fabrice Morand 
Date de l'opération : 2009 (PR)

1 Le massif domanial de Réno-Valdieu couvre une superficie d'environ 1500 ha. Il est le terrain d'élection d'un important peuplement de hêtres. Ce couvert forestier, attesté dès le $\mathrm{XI}^{\mathrm{e}} \mathrm{s}$., obtient le statut de forêt royale à l'époque Moderne. Aujourd'hui, dans des limites peu modifiées depuis l'Ancien Régime, la forêt est partagée entre cinq communes appartenant au parc naturel régional du Perche.

2 L'ensemble du massif colonise une ligne de crêtes dont l'altitude moyenne se situe autour de $211 \mathrm{~m}$ à $234 \mathrm{~m}$; ce bombement qui marque fortement le paysage est soustendu par des formations d'argile à silex, de limons et de sable du Perche. Les prospections ont permis d'identifier près d'une centaine de ferriers inédits. Ces emplacements typiques des activités de réduction du minerai de fer sont situés sur la hauteur de la forêt de Réno. Ils se caractérisent par la présence de scories plaques à cordon, résidus de bas-fourneaux, d'un type connu en forêt de Bellême.

3 La datation de ces ferriers, le plus souvent regroupés dans un rayon de $15 \mathrm{~m}$ à $30 \mathrm{~m}$, est délicate. Ce type d'exploitation est commun depuis la Protohistoire jusqu'à la fin du Moyen Âge. La fouille seule permettrait d'en évaluer la chronologie. Il faut noter que beaucoup de ces ateliers sidérurgiques se trouvent à proximité immédiate d'anciennes fosses d'extraction de minerai plus ou moins étendues. Dans certains cas, un fossé large d'à peine $0,70 \mathrm{~m}$ pour une profondeur de $0,30 \mathrm{~m}$ semble correspondre à une limite de concession, à moins qu'il ne s'agisse d'un simple drain.

4 Faisant suite à la prospection de la forêt de Bellême, le programme présent a montré tout l'intérêt de ce type d'opération en milieu forestier par la découverte d'un potentiel archéologique original. L'inventaire et le géoréférencement de ce patrimoine préindustriel ont été complétés par des prélèvements systématiques de scories pour servir aux études ultérieures.

Fabrice MORAND

\title{
AUTEURS
}

\author{
FABRICE MORAND
}

BEN 